Elevation of tumor necrosis factor alpha levels is associated with restless legs symptoms in clinically depressed patients

\title{
Auvinen, Piritta
}

2018-12

Auvinen , P , Mäntyselkä , P , Koponen , H, Kautiainen , H , Korniloff , K , Ahonen , T \& Vanhala , M 2018 , ' Elevation of tumor necrosis factor alpha levels is associated with restless legs symptoms in clinically depressed patients ' , Journal of Psychosomatic Research , vol. 115 . https://doi.org/10.1016/j.jpsychores.2018.09.008

http://hdl.handle.net/10138/308860

https://doi.org/10.1016/j.jpsychores.2018.09.008

publishedVersion

Downloaded from Helda, University of Helsinki institutional repository.

This is an electronic reprint of the original article.

This reprint may differ from the original in pagination and typographic detail.

Please cite the original version. 


\title{
Elevation of tumor necrosis factor alpha levels is associated with restless legs symptoms in clinically depressed patients
}

\author{
Piritta Auvinen $^{\mathrm{a}, *}$, Pekka Mäntyselkäa,b, Hannu Koponen ${ }^{\mathrm{c}}$, Hannu Kautiainen ${ }^{\mathrm{b}, \mathrm{d}}$, \\ Katariina Korniloff ${ }^{e}$, Tiina Ahonen ${ }^{f}$, Mauno Vanhala ${ }^{a}$ \\ ${ }^{a}$ Institute of Public Health and Clinical Nutrition, University of Eastern Finland, Kuopio, Finland \\ ${ }^{\mathrm{b}}$ Primary Health Care Unit, Kuopio University Hospital, Kuopio, Finland \\ c University of Helsinki, Helsinki University Hospital, Helsinki, Finland \\ ${ }^{\mathrm{d}}$ Folkhälsan Research Center, Helsinki, Finland \\ e School of Health and Social Studies, JAMK University of Applied Sciences, Jyväskylä, Finland \\ ${ }^{\mathrm{f}}$ Primary Health Care Unit, Central Finland Central Hospital, Jyväskylä, Finland
}

\section{A R T I C L E I N F O}

\section{Keywords:}

Restless legs syndrome

TNF-alpha

Depressive disorder

Depression

Primary health care

\begin{abstract}
A B S T R A C T
Background: Restless legs syndrome is a sensorimotor disorder associated with several mental illnesses particularly depression.

Methods: A cross-sectional study of primary care patients. The prevalence of restless legs symptoms was studied in 706 patients with depressive symptoms and 426 controls without a psychiatric diagnosis by using a structured questionnaire. The depressive symptoms were evaluated with the BDI and the psychiatric diagnosis was confirmed by means of a diagnostic interview (M.I.N.I.). The subjects with elevated depressive symptoms were divided into two groups subjects with depressive symptoms with and without clinical depression.

Results: The prevalence of restless legs symptoms was $24.8 \%$ in the controls, $50.0 \%$ in the patients with clinical depression and $42.4 \%$ in the patients with depressive symptoms. CRP value was significantly higher $(p=.003)$ in the clinically depressed patients than in the other groups. There was a higher concentration of TNF- $\alpha$ in the subjects with restless legs symptoms $(7.4 \mathrm{ng} / \mathrm{l} \pm 3.2)$ compared with the subjects without symptoms $(6.7 \mathrm{ng} /$ $1 \pm 2.3)(p<.001)$. There was a significant difference in the TNF- $\alpha$ levels between the subjects with and without restless legs symptoms in the depression group $(p<.001)$ and among the patients with depressive symptoms but no a depression diagnosis $(p=.022)$. In these groups, restless legs symptoms were associated with elevated levels of TNF- $\alpha$.

Conclusions: TNF- $\alpha$ level was associated with restless legs symptoms only among subjects with depressive symptoms whether they had clinical depression or not. We suggest that TNF- $\alpha$ could be an underlying factor between restless legs symptoms and comorbidities.
\end{abstract}

\section{Introduction}

Restless legs syndrome is a common sensorimotor disorder. Restless legs symptoms are characterized by an unpleasant sensation in the legs that appears at rest in the evening or during the night, but daytime symptoms are not exclude. In addition, patients suffer from an urge to move their legs and moving or stretching the legs relieves the symptoms $[1,2]$. In previous studies, the prevalence of restless legs syndrome has been between $4 \%$ and $29 \%$ [3]. Among primary care patients, the prevalence has been found to be $24 \%$ to $25 \%[4,5]$. Knowledge about the pathophysiology of restless legs syndrome and clinical experience have increased during the last decade, but the exact pathophysiology is still obscure [6].

Several different theories on the cause of restless legs syndrome have been suggested, such as deficient dopaminergic neurotransmission, iron deficiency, hormones, genetics, peripheral hypoxia, neuroinflammation and a lack of folate [7-12]. A lack of iron metabolism is more about the central nervous system than the peripheral parts, it affects dopaminergic function, thereby disturbing monoamine neurotransmitter synthesis [9]. For its part this could explicate the presences of depressive symptoms alongside of restless legs symptoms [13]. There are numerous studies on the relationship between depressed mood or depression and restless legs syndrome [14,15]. The fundamental causes that binds depression and restless legs symptoms together is unresolved.

\footnotetext{
* Corresponding author at: University of Eastern Finland, Primary Health Care Unit, P.O.B. 1627, FI-70211 Kuopio, Finland.

E-mail address: pirau@student.uef.fi (P. Auvinen).
} 
Notwithstanding, the relationship between tumor necrosis factor alpha (TNF- $\alpha$ ) and depression is intricate. The activity of TNF- $\alpha$ is possibly linked to several other diseases such as psoriasis, rheumatoid arthritis and inflammatory bowel disease [16-18]. TNF- $\alpha$ is a member of a superfamily of proteins and it is most accurately a pleiotropic cytokine. TNF- $\alpha$ is a crucial factor intrinsic to the immune system's proinflmmatory actions. Many divergent cells, e.g., activated macrophages, monocytes, T-cells, lymphocytes and astrocytes, have the capacity for produce TNF- $\alpha$ [17]. Major theories that have linked TNF- $\alpha$ and depression together are revision on the hypothalamic-pituitaryadrenal-axis, genetic polymorphisms and changes in serotonin and dopamine transporters [19]. According to former studies, especially elevated levels of TNF- $\alpha$ have not had a conclusive link to depression [20-24], but this connection invariably exists [25,26]. The relation between TNF- $\alpha$ and restless legs syndrome has proved to be insignificant [27].

Previously, a commonly used inflammation marker- $C$ reactiveprotein (CRP) - activates the synthesis of interleukin- 6 and TNF- $\alpha$ and most of all is associated with bacterial inflammation, tissue injury or stress but CRP has been found to be connected to depression [28,29]. The relationship between CRP and restless legs syndrome was negligible in a previous study [30]. However, another study suggested that systemic low-grade inflammation might play a role in restless legs symptoms [27]. Thus, inflammation could be one factor linking restless legs symptoms to depression. A relationship between depression, restless legs symptoms and inflammation markers, including CRP and TNF$\alpha$, has not been studied before at lenght thus the relationship required more searching.

\section{Aims}

Due to non-existent data on the correlation between TNF- $\alpha$, restless legs symptoms and a diagnosis or symptoms of depression, we decided to study this relationship in a geographically defined sample of patients with depressive symptoms with and without clinical depression and population-based control subjects without a psychiatric diagnosis. We hypothesized that TNF- $\alpha$ may have a role in the elevated presentation of restless legs symptoms among depressed subjects.

\section{Material and methods}

New patients aged 35 years or older who went themselves or were referred by a general practitioner to a depression nurse case manager in 2008-2009 due to depressive symptoms and a score of least 10 in the 21-item Beck's Depression Inventory (BDI) were enlisted in this study. Altogether 706 patients were involved. The study (the Finnish Depression and Metabolic Syndrome in Adults study, FDMSA) was conducted in municipalities belonging to the Central Finland Hospital District, with a catchment area of 274,000 residents. Notification was based on written and oral patient information and written consent was obtained before any study procedures. The study protocol was approved by the Ethics Committee of the Central Finland Hospital District. The FDMSA -study has been reported in previous studies [31-35].

Random sampling was used to select a group of 426 middle-aged ( $>35$ years) persons as controls from among residents in the participating municipalities. Concurrently with the patient recruitment in 2008-2009, an age, sex and community stratified random sample representing the population in the study region was taken by Statistics of Finland (http://www.stat.fi). Statistics of Finland is independent organization under the Ministry of Finance and manages the data from administrative registers in Finland. All the subjects in the control group had a BDI score below 10 and no psychiatric diagnosis or current depressive symptoms and they used no psychoactive medications. A total of 27 subjects in the study groups did not answer the question about restless legs symptoms. To eschew misrepresented results, the data do not include subjects $(N=78)$ c-reactive protein (CRP) values over
$30 \mathrm{mg} / \mathrm{l}$ or TNF- $\alpha$ values over $50 \mathrm{ng} / \mathrm{l}$, ensuring that microbe based contamination would not excessively impact the results [36,37].

All the participants filled in a standard questionnaire form containing questions about previously diagnosed somatic disorders and use of medications, including antidepressants and hormone replacement therapy in females. Data on current smoking, years of education, use of alcohol (number of drinks per week) and leisure-time physical activity (number of 30-min exercise sessions) were also collected. Leisure-time physical activity was determined with the question:" How often do you do physical activity at least half on hour so that you are out of breath and sweating?" then answers were classified as low (0-2 sessions per month), moderate (1-2 sessions per week), or high (three or more sessions per week) [35].

The depressive symptoms were evalueted with the 21-item Beck's Depression Inventory (BDI) [38], which was completed by the participants. The psychiatric diagnosis was confirmed with a diagnostic interview (Mini-International Neuropsychiatric Interview; M.I.N.I. [39]) conducted by a trained study nurse [40]. Out of the whole study population, 439 subjects had a BDI score of 10 or higher and a diagnosis of depression determined with the diagnostic interview (M.I.N.I.) $[39,41,42]$.

Restless legs symptoms were detected with a structured and tested question that takes into account the core characteristics of restless legs syndrome discomfort: an urge to move the legs, primarily during rest or inactivity, and partial or total relief with movement, with the presence or worsening of discomfort exclusively in the evening or at night. According to a previous validation study, the questionnaire had $100 \%$ sensitivity and $96.8 \%$ specificity. Moreover, the likelihood ratio for a positive result ( $\mathrm{LR}+=31,25$ ) adverted to the positive test had a conclusive elevate in the probability of restless legs syndrome [43].

The blood sample collection procedure happened in the health centre's laboratories by educated nurse and in an outpatient setting. Glucose and lipid level determinations were based on fasting blood samples drawn between 8 and 11 o'clock after $12 \mathrm{~h}$ of fasting. TNF- $\alpha$ was determined from freezed samples and cocentration was analyzed using an Immulite 1000 immunoassay analyzer (Siemens Healthcare Diagnostics Products Ltd., Gwynedd, UK). Serum total cholesterol, HDL cholesterol, LDL cholesterol, triglycerides and plasma glucose were analyzed using Modular Analytics SWA (Hitachi High-Technologies Corporation, Tokyo, Japan).

\subsection{Statistical analysis}

Statistical comparisons between the groups was done by analysis of variance (ANOVA), Kruskal-Wallis test, Chi-Square test or FisherFreeman-Halton test, when appropriate. When adjusted models were used, analysis of covariance (ANCOVA) was applied; the models included age, smoking, alcohol use, body mass index and physical activity as covariates. In the case of violation of the assumptions (e.g. nonnormality), a bootstrap-type method was used (10,000 replications) to estimate standard error. The normality of variables was evaluated by the Shapiro-Wilk W test. All the analyses were performed using STATA 15.0.

\section{Results}

A total of 1027 subjects, comprising the patients and controls, participated in our study; (33.0\%) men and 688 (67.0\%) women. Of these subjects, 396 were controls with no psychiatric diagnosis, 243 were patients with depressive symptoms without a depression diagnosis and 388 patients had received a depression diagnosis. All the subjects with elevated depressive symptoms and the clinically depressed patients had higher triglyceride levels, lower leisure time physical activity and higher body mass index (BMI) than the controls. Furthermore, the prevalence of current smoking was higher in the patient groups than in the controls. The clinically depressed patients had a significally higher 
Table 1

Demographic and clinical traits of the subjects.

\begin{tabular}{|c|c|c|c|c|}
\hline & \multirow{2}{*}{$\begin{array}{l}\text { Controls (A) } \\
N=396\end{array}$} & \multicolumn{2}{|l|}{$\mathrm{BDI} \geq 10$} & \multirow[t]{2}{*}{$P$-value } \\
\hline & & $\begin{array}{l}\text { Without depression (B) } \\
N=243\end{array}$ & $\begin{array}{l}\text { Depression (C) } \\
N=388\end{array}$ & \\
\hline Female, n (\%) & 234 (59) & $180(74)$ & $274(71)$ & $<0.001$ \\
\hline Age, mean (SD) & $53(10)$ & $54(11)$ & $51(10)$ & 0.002 \\
\hline Education years, mean (SD) & $11.9(3.4)$ & $11.0(3.3)$ & $11.0(3.1)$ & $<0.001$ \\
\hline Body Mass Index, mean (SD) & $26.7(4.6)$ & $27.9(6.0)$ & $27.9(5.6)$ & 0.005 \\
\hline Smoking, n (\%) & $64(16)$ & $56(23)$ & $127(33)$ & $<0.001$ \\
\hline Alcohol use dose, n (\%) & & & & 0.088 \\
\hline 0 & $65(16)$ & $58(24)$ & $91(23)$ & \\
\hline $1-9$ & $282(71)$ & $158(65)$ & $248(64)$ & \\
\hline$\geq 10$ & $49(12)$ & $27(11)$ & $49(13)$ & \\
\hline Leisure time physical activity, n (\%) & & & & $<0.001_{*}$ \\
\hline Low & $46(12)$ & $40(17)$ & $98(25)$ & \\
\hline Moderate & $173(44)$ & $118(49)$ & $157(41)$ & \\
\hline High & $177(45)$ & $84(35)$ & $132(34)$ & \\
\hline \multicolumn{5}{|l|}{$\mathrm{BP}, \mathrm{mmHg}$, mean (SD) } \\
\hline Systolic & $129(16)$ & $130(16)$ & $130(16)$ & 0.50 \\
\hline Diastolic & $81(10)$ & $81(10)$ & $82(10)$ & 0.58 \\
\hline Plasma glucose, mmol/l, mean (SD) & $5.67(0.99)$ & $5.64(0.86)$ & $5.85(1.37)$ & 0.042 \\
\hline Serum cholesterol, mmol/1, mean (SD) & $5.05(0.88)$ & $5.12(0.95)$ & $5.09(1.03)$ & 0.67 \\
\hline Serum LDL cholesterol, mmol/l, mean (SD) & $3.11(0.82)$ & $3.11(0.84)$ & $3.05(0.94)$ & 0.66 \\
\hline Serum HDL cholesterol, mmol/l, mean (SD) & $1.57(0.42)$ & $1.57(0.45)$ & $1.57(0.48)$ & 0.99 \\
\hline $\begin{array}{l}\text { Serum triglycerides, mmol/l, mean } \\
\quad \text { (SD) }\end{array}$ & $1.21(0.66)$ & $1.37(1.65)$ & $1.36(0.83)$ & 0.012 \\
\hline C-reactive protein, mg/l (SD) & $2.62(3.41)$ & $2.58(3.31)$ & $3.55(4.84)$ & 0.003 \\
\hline Tumor necrosis factor alpha (SD) & $6.9(2.7)$ & $7.1(3.2)$ & $7.0(2.4)$ & 0.65 \\
\hline Antidepressant medication (\%) & $20(5)$ & $118(49)$ & 267 (69) & $<0.001$ \\
\hline
\end{tabular}

Results in the table shown as numbers (percentage) and means (standard deviation).

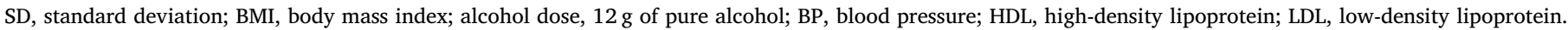

* low $p<.001$, moderate $p=.13$ and high $p<.001$.

plasma glucose values and CRP than the controls. (Table 1).

Restless legs symptoms were present in 395 (38.5\%) of the study subjects. There was a significant difference in the prevalence of restless legs symptoms between study groups $(P<.001$; adjusted for sex, age, smoking, alcohol use, BMI and physical activity). The controls had the lowest prevalence of restless legs symptoms: $24.8 \%$. The patients with depressive symptoms without a depression diagnosis had a $42.4 \%$ prevalence of restless legs symptoms and the highest prevalence $50.0 \%$ was found among the clinically depressed patients.

The average concentration of TNF- $\alpha$ was $7.0 \mathrm{ng} / \mathrm{l}$. There was no noteworthy difference in the concentration of TNF- $\alpha$ between the controls and the depressive patients groups. The concentration of TNF$\alpha$ was statistically significantly higher in the subjects with restless legs symptoms $(7.4 \mathrm{ng} / \mathrm{l} \pm 3.2)$ as compared to the subjects without restless legs symptoms $(6.7 \mathrm{ng} / 1 \pm 2.3)(p<.001$ adjusted for sex, age, smoking, alcohol use, body mass index and physical activity).

Fig. 1 shows that in general there was a significant difference ( $p=.005)$ in the levels of TNF- $\alpha$ between the subjects with and without restless legs symptoms. In the clinically depressed patients $(p=.005)$ and among the patients with depressive symptoms without a depression diagnosis $(p=.006)$ restless legs symptoms were significantly associated with elevated levels of TNF- $\alpha$. However, among the control subjects, the TNF- $\alpha$ levels were similar with and without restless legs symptoms. Furthermore we discovered not significant difference in concentration of TNF- $\alpha$ between atypical and melancholic depression subtypes, regardless of restless legs symptoms. There were no differences in TNF- $\alpha$ levels between the patient groups and the controls if restless legs symptoms was not taken into consideration. The other marker of inflammation, CRP, did not have a similar association to restless legs symptoms.

\section{Discussion}

The novel finding in our study was that in the subjects with depressive symptoms with and without clinical depression, elevated circulating TNF- $\alpha$ was found only in those with having restless legs symptoms. Contrary to that finding, the levels of TNF- $\alpha$ were similar in the control group regardless of restless legs symptoms. Based on these results, we propose that TNF- $\alpha$ may have a noteworthy role in the manifestation of restless legs symptoms, particularly in depressive patients.

The prevalence of restless legs symptoms was $24.8 \%$ in the controls. Respectively, previous population studies have reported the prevalence of restless legs syndrome that estimates as high as $24 \%$ [43-45], and among patients with depression the prevalence that estimates as high as $31.5 \%$ [46]. The association between TNF- $\alpha$ and depression is not significant constantly; for instance, obesity may confuse the correspondence [47]. The present study suggests that among people with depressive symptoms or clinical depression, elevated circulating TNF- $\alpha$ levels are linked to a comorbid background factor such as manifesting as restless legs symptoms.

Previous studies have found TNF- $\alpha$ potency to initiate divalent metal transporter 1 (DMT1) onset, whereupon iron uptake increase in the astrocytes, microglia and neurons $[48,49]$. Iron has an influence on, e.g., DNA synthesis and protein metabolism including dopamine and serotonin synthesis [50]. Another conceivable theory is connected to TNF- $\alpha$ 's impact on monoaminergic systems, including the functions of dopamine and serotonin. Elevated plasma TNF- $\alpha$ improved indoleamine 2,3-dioxygenase (IDO) activity in peripheral and brain tissues [51]. IDO precipitated depression inhibiting development of tryptophan to serotonin [52] and TNF- $\alpha$ decreased the bioavaibility of serotonin and had an effect on reuptaking of serotonin [53].

Previous studies have shown that anti-TNF- $\alpha$ treatment, precisely infliximab, diminished depressive symptoms or depression in patients with other diseases, e.g., Crohn's disease and ankylosing spondylitis, and the activity of the disease did not have an impact on outcome $[54,55]$. Infliximab relieved depression-like behavior in mice [51], but in a patient study infliximab did not enhance treatment-resistant 

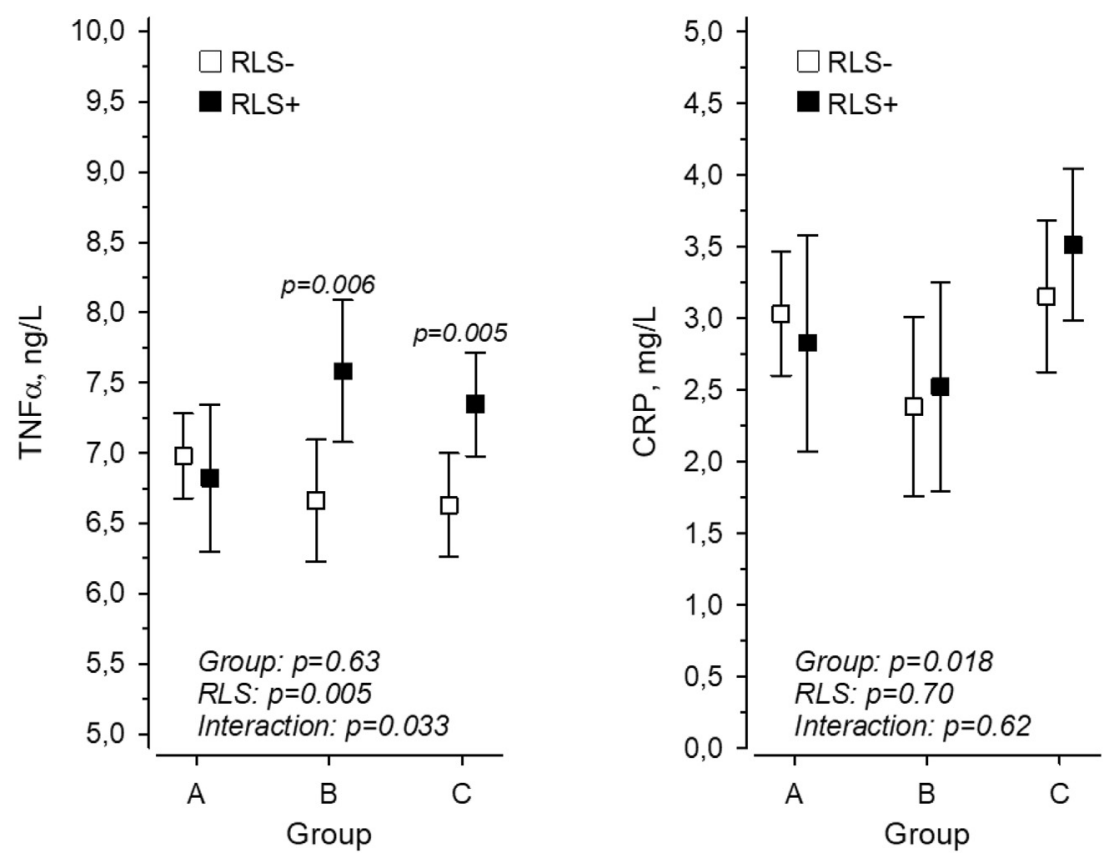

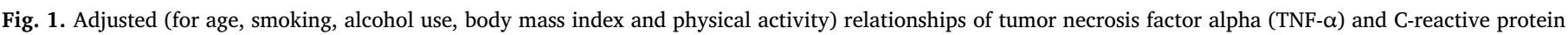
(CRP) restless legs symptoms in controls (A), subjects with depressive symptoms without a depression diagnosis (B) and clinically depressed patients (C).

depression [56]. Could we consider the use of anti-TNF- $\alpha$ treatment for depression as a cause of grievous restless legs symptoms? Conceivable drawbacks of anti-TNF- $\alpha$ treatment are infections [57], whereupon, a disadvantage of the treatment is that it hinders rather than helps.

In our study, the clinically depressed patients had higher CRP levels than the controls, which has been common for CRP also in previous studies [58]. The data showed that CRP level did not have an influence on the occurence of restless legs symptoms in the depressive patients. Our finding suspected the pathophysiology of restless legs symptoms to includ effects of the immune system, but the association between CRP and restless legs symptoms was not the most likely alternative [59]. There was strong evidence that CRP is a more probabilistic immune marker alternative, overarching to unambiguous depression, than TNF$\alpha[24]$.

The strengths of our investigation included a geographically representative sample of middle-aged and elderly subjects. Moreover, the diagnosis of depression was based on a diagnostic interview besides self-reported depressive symptoms. However, the diagnostic interview did not contain questions about restless legs symptoms. The data regarding restless legs symptoms were based on structured questionnaire enquiring about self-reported symptoms. The study did not take into consideration differentiating between idiopathic, secondary, or iatrogenic restless legs symptoms, which is a limitation.

It can be possible that simple sentence questionnaire with a high sensitivity and specificity endorsed by Ferri et al. in 2007 could cause false positive responses [43]. However, it is comparable with some other studies using criteria developed by International Restless Legs Syndrome Study Group [44]. Another limitation is the cross-sectional design of our study, which does not justify making inferences of the causality of TNF- $\alpha$ and restless legs symptoms. Additionally, only persons aged 35 or older were enrolled in the study, so the results can not be generalized to younger age groups.

These findings suggest a role for neuroinflammation in the genesis of restless legs symptoms in the patients with depressive symptoms with and without clinical depression but differentiating and origin of the restless legs symptoms require further clarification. This study may have some clinical implications and it prompts further studies because to our knowledge this is the first study that has presented a relationship between TNF- $\alpha$ and restless legs symptoms in depressive patients. We conclude that based on the present results elevated circulating TNF- $\alpha$ levels are associated with restless legs symptoms in subjects with depressive symptoms with and without clinical depression, but not in subjects with no depressive symptoms.

\section{Funding}

This study was supported by the Central Finland Health Care District.

\section{Ethical approval}

The study protocol was approved on the 17th of April 2007 by the Ethics Committee of Central Finland Central Hospital.

\section{Competing interests}

The authors have declared no competing interests.

\section{Acknowledgements}

The authors thank the following nurse case managers who took part in the practical implementation of the FDMSA: Mari Alanko, Harri Back, Timo Hannula, Anu Holopainen, Ritva Häkkinen, Katja Johansson, Eija Kinnunen, Kaija Luoma, Hannele Niemi, Hillevi Peura, Inga Pöntiö, Kirsi Rouvinen, Tiina Silvennoinen and Marianne Vihtamäki, as well as FDMSA study nurses Anne Kirmanen, Reetta Oksanen and Olli Niemi, and Pia Jauhiainen, the scientific secretary of the study.

\section{References}

[1] R.P. Allen, D.L. Picchietti, D. Garcia-Borreguero, W.G. Ondo, A.S. Walters, J.W. Winkelman, et al., Restless legs syndrome/Willis-Ekbom disease diagnostic criteria: updated International Restless Legs Syndrome Study Group (IRLSSG) consensus criteria-history, rationale, description, and significance, Sleep Med. 15 (8) (2014 Aug) 860-873.

[2] M. Takahashi, J. Ikeda, T. Tomida, K. Hirata, N. Hattori, Y. Inoue, Daytime symptoms of restless legs syndrome-clinical characteristics and rotigotine effectiveness, Sleep Med. 16 (7) (2015 Jul) 871-876.

[3] K.E. Innes, T.K. Selfe, P. Agarwal, Prevalence of restless legs syndrome in north 
American and Western European populations: a systematic review, Sleep Med. 12 (7) (2011 Aug) 623-634.

[4] K.E. Innes, T.K. Selfe, P. Agarwal, Prevalence of restless legs syndrome in north American and Western European populations: a systematic review, Sleep Med. 12 (7) (2011 Aug) 623-634

[5] M.M. Ohayon, R. O'Hara, M.V. Vitiello, Epidemiology of restless legs syndrome: a synthesis of the literature, Sleep Med. Rev. 16 (4) (2012 Aug) 283-295.

[6] D.L. Picchietti, S.K. Van Den Eeden, Y. Inoue, K. Berger, Achievements, challenges, and future perspectives of epidemiologic research in restless legs syndrome (RLS), Sleep Med. 31 (2017) 3-9.

[7] R.P. Allen, C. Chen, D. Garcia-Borreguero, O. Polo, S. Dubrava, J. Miceli, et al., Comparison of pregabalin with pramipexole for restless legs syndrome, N. Engl. J. Med. 370 (7) (2014 Feb 13) 621-631.

[8] J.R. Connor, S.M. Patton, K. Oexle, R.P. Allen, Iron and restless legs syndrome: treatment, genetics and pathophysiology, Sleep Med. 31 (2017 Mar) 61-70.

[9] F.H. Khan, C.D. Ahlberg, C.A. Chow, D.R. Shah, B.B. Koo, Iron, dopamine, genetics, and hormones in the pathophysiology of restless legs syndrome, J. Neurol. 264 (8) (2017 Aug) 1634-1641.

[10] B. Schormair, C. Zhao, S. Bell, E. Tilch, A.V. Salminen, B. Putz, et al., Identification of novel risk loci for restless legs syndrome in genome-wide association studies in individuals of European ancestry: a meta-analysis, Lancet Neurol. 16 (11) (2017 Nov) 898-907.

[11] A.V. Salminen, V. Rimpila, O. Polo, Peripheral hypoxia in restless legs syndrome (Willis-Ekbom disease), Neurology 82 (21) (2014 May 27) 1856-1861.

[12] K.A. Lee, M.E. Zaffke, K. Baratte-Beebe, Restless legs syndrome and sleep disturbance during pregnancy: the role of folate and iron, J Womens Health Gend Based Med. 10 (4) (2001 May) 335-341.

[13] G. Rizzo, X. Li, S. Galantucci, M. Filippi, Y.W. Cho, Brain imaging and networks in restless legs syndrome, Sleep Med. 31 (2017) 39-48.

[14] J. Winkelmann, M. Prager, R. Lieb, H. Pfister, B. Spiegel, H.U. Wittchen, et al. Anxietas tibiarum. Depression and anxiety disorders in patients with restless legs syndrome, J. Neurol. 252 (1) (2005 Jan) 67-71.

[15] H.B. Lee, W.A. Hening, R.P. Allen, A.E. Kalaydjian, C.J. Earley, W.W. Eaton, et al., Restless legs syndrome is associated with DSM-IV major depressive disorder and panic disorder in the community, J Neuropsychiatry Clin Neurosci. 20 (1) (2008) $101-105$.

[16] M.E. Killeen, L. Ferris, E.A. Kupetsky, L. Falo, A.R. Mathers, Signaling through purinergic receptors for ATP induces human cutaneous innate and adaptive Th17 responses: implications in the pathogenesis of psoriasis, J. Immunol. 190 (8) (2013 Apr 15) 4324-4336.

[17] Z. Dembic, The Cytokines of the Immune System : The Role of Cytokines in Disease Related to Immune Response, online resource, 2015.

[18] T.P. Rossard, T.P. Rossard, Tumor Necrosis Factor, (2009), p. 246.

[19] K. Ma, H. Zhang, Z. Baloch, Pathogenetic and Therapeutic applications of Tumor Necrosis Factor-alpha (TNF-alpha) in Major Depressive Disorder: a Systematic Review, Int. J. Mol. Sci. 17 (5) (2016 May 14), https://doi.org/10.3390/ ijms17050733.

[20] J. Dahl, H. Ormstad, H.C. Aass, U.F. Malt, L.T. Bendz, L. Sandvik, et al., The plasma levels of various cytokines are increased during ongoing depression and are reduced to normal levels after recovery, Psychoneuroendocrinology 45 (2014 Jul) 77-86.

[21] K. Becking, L. Boschloo, N. Vogelzangs, B.C. Haarman, R. Riemersma-Van Der Lek, B.W. Penninx, et al., The association between immune activation and manic symptoms in patients with a depressive disorder, Transl. Psychiatry 3 (2013 Oct 22) e314.

[22] L. Grosse, O. Ambree, S. Jorgens, M.C. Jawahar, G. Singhal, D. Stacey, et al., Cytokine levels in major depression are related to childhood trauma but not to recent stressors, Psychoneuroendocrinology 73 (2016 Nov) 24-31.

[23] R.A. Charlton, M. Lamar, A. Zhang, X. Ren, O. Ajilore, G.N. Pandey, et al., Associations between pro-inflammatory cytokines, learning, and memory in late-life depression and healthy aging, Int J Geriatr Psychiatry. 33 (2018) 104-112.

[24] R. Haapakoski, J. Mathieu, K.P. Ebmeier, H. Alenius, M. Kivimaki, Cumulative meta-analysis of interleukins 6 and 1beta, tumour necrosis factor alpha and C-reactive protein in patients with major depressive disorder, Brain Behav. Immun. 49 (2015 Oct) 206-215.

[25] D.R. Goldsmith, M.H. Rapaport, B.J. Miller, A meta-analysis of blood cytokine network alterations in psychiatric patients: comparisons between schizophrenia, bipolar disorder and depression, Mol. Psychiatry 21 (12) (2016 Dec) 1696-1709.

[26] Y. Liu, R.C. Ho, A. Mak, Interleukin (IL)-6, tumour necrosis factor alpha (TNFalpha) and soluble interleukin-2 receptors (sIL-2R) are elevated in patients with major depressive disorder: a meta-analysis and meta-regression, J. Affect. Disord. 139 (3) (2012 Aug) 230-239.

[27] L.M. Trotti, D.B. Rye, C. De Staercke, W.C. Hooper, A. Quyyumi, D.L. Bliwise, Elevated C-reactive protein is associated with severe periodic leg movements of sleep in patients with restless legs syndrome, Brain Behav. Immun. 26 (8) (2012 Nov) 1239-1243.

[28] V. Valkanova, K.P. Ebmeier, C.L. Allan, CRP, IL-6 and depression: a systematic review and meta-analysis of longitudinal studies, J. Affect. Disord. 150 (3) (2013 Sep 25) 736-744.

[29] T.B. Ledue, N. Rifai, Preanalytic and analytic sources of variations in C-reactive protein measurement: implications for cardiovascular disease risk assessment, Clin. Chem. 49 (8) (2003 Aug) 1258-1271.

[30] B. Benediktsdottir, C. Janson, E. Lindberg, E.S. Arnardottir, I. Olafsson, E. Cook, et al., Prevalence of restless legs syndrome among adults in Iceland and Sweden: Lung function, comorbidity, ferritin, biomarkers and quality of life, Sleep Med. 11 (10) (2010 Dec) 1043-1048.

[31] K. Korniloff, S. Kotiaho, M. Vanhala, H. Kautiainen, H. Koponen, P. Mantyselka, Musculoskeletal Pain in Melancholic and Atypical Depression, Pain Med. 18 (2) (2017 Feb 1) 341-347.

[32] P. Auvinen, P. Mantyselka, H. Koponen, H. Kautiainen, K. Korniloff, T. Ahonen, et al., Prevalence of restless legs symptoms according to depressive symptoms and depression type: a cross-sectional study, Nord J Psychiatry. 72 (1) (2018 Jan) 51-56.

[33] H. Koponen, H. Kautiainen, E. Leppanen, P. Mantyselka, M. Vanhala, Cardiometabolic risk factors in patients referred to depression nurse case managers, Nord J Psychiatry. 69 (4) (2015 May) 262-267.

[34] H. Koponen, H. Kautiainen, E. Leppänen, P. Mäntyselkä, M. Vanhala, Association between suicidal behaviour and impaired glucose metabolism in depressive disorders, BMC Psychiatry. 15 (2015 Jul 22) 163.

[35] I. Raatikainen, M. Vanhala, P. Mäntyselkä, A. Heinonen, H. Koponen, H. Kautiainen, et al., Does level of leisure time physical activity, in a sample of patients with depression, predict health care utilization over a subsequent 5-year period? Findings from a Finnish cohort study, Ment. Health and Phys. Act. 15 (2018) 40-44.

[36] P. Póvoa, C-reactive protein: a valuable marker of sepsis, Intensive Care Med. 28 (3) (2002 Mar) 235-243.

[37] O. Rigato, S. Ujvari, A. Castelo, R. Salomão, Tumor necrosis factor alpha (TNFalpha) and sepsis: evidence for a role in host defense, Infection 24 (4) (1996 JulAug) 314-318.

[38] A.T. Beck, A systematic investigation of depression, Compr. Psychiatry 2 (3) (1961) 163-170.

[39] D.V. Sheehan, Y. Lecrubier, J. Janavs, Mini-International Neuropsychiatric Interview (MINI), University of South Florida. Institute for Research in Psychiatry, Tampa, FL, 1994.

[40] H. Koponen, H. Kautiainen, E. Leppänen, P. Mäntyselkä, M. Vanhala, Cardiometabolic risk factors in patients referred to depression nurse case managers, Nord J Psychiatry. 69 (4) (2015 May) 262-267.

[41] Y. Ovaskainen, H. Koponen, J. Jokelainen, S. Keinanen-Kiukaanniemi, E. Kumpusalo, M. Vanhala, Depressive symptomatology is associated with decreased interleukin-1 beta and increased interleukin-1 receptor antagonist levels in males, Psychiatry Res. 167 (1-2) (2009 May 15) 73-79.

[42] M. Vanhala, J. Jokelainen, S. Keinanen-Kiukaanniemi, E. Kumpusalo, H. Koponen, Depressive symptoms predispose females to metabolic syndrome: a 7-year follow-up study, Acta Psychiatr. Scand. 119 (2) (2009 Feb) 137-142.

[43] R. Ferri, B. Lanuzza, F.I.I. Cosentino, I. Iero, M. Tripodi, R.S. Spada, et al., A single question for the rapid screening of restless legs syndrome in the neurological clinical practice, Eur. J. Neurol. 14 (9) (2007) 1016-1021.

[44] D.A. Nichols, R.P. Allen, J.H. Grauke, J.B. Brown, M.L. Rice, P.R. Hyde, et al, Restless legs syndrome symptoms in primary care: a prevalence study, Arch. Intern. Med. 163 (19) (2003 Oct 27) 2323-2329.

[45] S. Celle, F. Roche, J. Kerleroux, C. Thomas-Anterion, B. Laurent, I. Rouch, et al., Prevalence and clinical correlates of restless legs syndrome in an elderly French population: the synapse study, J. Gerontol. A Biol. Sci. Med. Sci. 65( (2) (2010 Feb) $167-173$

[46] R. Gupta, V. Lahan, D. Goel, Prevalence of restless leg syndrome in subjects with depressive disorder, Indian J. Psychiatry 55 (1) (2013 Jan) 70-73.

[47] F.M. Schmidt, N. Lichtblau, J. Minkwitz, T. Chittka, J. Thormann, K.C. Kirkby, et al., Cytokine levels in depressed and non-depressed subjects, and masking effects of obesity, J. Psychiatr. Res. 55 (2014 Aug) 29-34.

[48] P. Urrutia, P. Aguirre, A. Esparza, V. Tapia, N.P. Mena, M. Arredondo, et al., Inflammation alters the expression of DMT1, FPN1 and hepcidin, and it causes iron accumulation in central nervous system cells, J. Neurochem. 126 (4) (2013 Aug) $541-549$.

[49] K.I. Rathore, A. Redensek, S. David, Iron homeostasis in astrocytes and microglia is differentially regulated by TNF-alpha and TGF-beta1, Glia 60 (5) (2012 May) 738-750.

[50] J. Kim, M. Wessling-Resnick, Iron and mechanisms of emotional behavior, J. Nutr. Biochem. 25 (11) (2014 Nov) 1101-1107.

[51] Y.N. Liu, Y.L. Peng, L. Liu, T.Y. Wu, Y. Zhang, Y.J. Lian, et al., TNFalpha mediates stress-induced depression by upregulating indoleamine 2,3-dioxygenase in a mouse model of unpredictable chronic mild stress, Eur. Cytokine Netw. 26 (1) (2015) $15-25$.

[52] P. Kopschina Feltes, J. Doorduin, H.C. Klein, L.E. Juárez-Orozco, R.A. Dierckx, C.M. Moriguchi-Jeckel, et al., Anti-inflammatory treatment for major depressive disorder: implications for patients with an elevated immune profile and non-responders to standard antidepressant therapy, J Psychopharmacol (Oxford). 31 (9) (2017 Sep) 1149-1165.

[53] D. Baumeister, S. Ciufolini, V. Mondelli, Effects of psychotropic drugs on inflammation: consequence or mediator of therapeutic effects in psychiatric treatment? Psychopharmacology 233 (9) (2016 May) 1575-1589.

[54] S. Guloksuz, M. Wichers, G. Kenis, Maurice G.V.M. Russel, A. Wauters, R. Verkerk, et al., Depressive Symptoms in Crohn's Disease: Relationship with Immune Activation and Tryptophan Availability, PLoS One 8 (3) (2013) 1-8.

[55] I. Ertenli, S. Ozer, S. Kiraz, S.B. Apras, A. Akdogan, O. Karadag, et al., Infliximab, a TNF-alpha antagonist treatment in patients with ankylosing spondylitis: the impact on depression, anxiety and quality of life level, Rheumatol. Int. 32 (2) (2012 Feb) $323-330$.

[56] C.L. Raison, R.E. Rutherford, B.J. Woolwine, C. Shuo, P. Schettler, D.F. Drake, et al., A randomized controlled trial of the tumor necrosis factor antagonist infliximab for treatment-resistant depression: the role of baseline inflammatory biomarkers, JAMA Psychiatry. 70 (1) (2013 Jan) 31-41.

[57] H. Rosenblum, H. Amital, Anti-TNF therapy: safety aspects of taking the risk, Autoimmun. Rev. 10 (9) (2011 Jul) 563-568.

[58] M.S. Cepeda, P. Stang, R. Makadia, Depression is associated with high levels of creactive protein and low levels of fractional exhaled nitric oxide: results from the 2007-2012 National Health and Nutrition Examination surveys, J Clin Psychiatry. 77 (12) (2016 Dec) 1666-1671.

[59] B. Benediktsdottir, C. Janson, E. Lindberg, E.S. Arnardottir, I. Olafsson, E. Cook, et al., Prevalence of restless legs syndrome among adults in Iceland and Sweden: Lung function, comorbidity, ferritin, biomarkers and quality of life, Sleep Med. 11 (10) (2010 Dec) 1043-1048. 